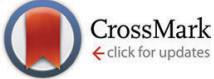

Cite this: Phys. Chem. Chem. Phys., 2015, 17, 11950

Received 9th February 2015 Accepted 8th April 2015

DOI: $10.1039 / \mathrm{c5}$ cp00834d

www.rsc.org/pccp

\section{The effect of structure directing agents on the ordering of fluoride ions in pure silica MFI zeolites $\uparrow$}

\author{
S. L. Brace, ${ }^{a}$ P. Wormald ${ }^{b}$ and R. J. Darton ${ }^{\star a}$
}

The effect of different sizes of structure directing agents on the ordering of the fluoride ions in pure silica MFI zeolites has been determined using magic angle spinning solid state NMR. By synthesizing fluoride containing pure silica MFI zeolites using methyltributylammonium cations as the structure directing agent, it has been possible to change the type of ordering seen for the fluoride ions at room temperature from the previously reported dynamic to static disorder. An initial mechanism for how this fluoride ordering occurs is suggested based upon the coulombic interaction between the positive charge on the nitrogen and the negative fluoride ion, within the zeolite framework, with different sizes of tetraalkylammonium cations.

Zeolites are highly ordered crystalline solids that contain numerous pores and voids, the sizes of which are influenced by the shape of the organic structure directing agent (SDA) used in the synthesis. It is these well-defined architectures that have led to the extensive use of zeolites as catalysts, ion-exchangers and for gas storage. Traditionally, zeolites have been synthesised using hydroxide ions as mineralising agents, which introduce defects in to the framework that are needed to balance the charge on the organic SDAs. The more recent introduction of fluoride ions into high silica zeolite syntheses has led to significantly less defects due to the incorporated fluoride anions balancing the charge on the organic cations. ${ }^{1}$ The use of fluoride ions in zeolite syntheses has produced some interesting results including the preparation of larger single crystals $^{2}$ and some new framework types. ${ }^{3,4}$ In addition to its mineralising role, where it helps to solvate silica species, it has also been proposed that the fluoride ions act as a catalyst for the condensation reaction that leads to the production of

\footnotetext{
${ }^{a}$ Catalysis and Sustainable Materials Group, Lennard-Jones Laboratories, Keele University, Staffordshire, ST5 5BG, UK. E-mail: r.j.darton@keele.ac.uk ${ }^{b}$ School of Chemistry, University of St Andrews, St Andrews, Fife, KY16 9ST, UK $\dagger$ Electronic supplementary information (ESI) available: Sample synthesis and characterization data, MAS NMR experimental details, deconvoluted ${ }^{29} \mathrm{Si}$ NMR spectra, ${ }^{13} \mathrm{C}$ and ${ }^{19} \mathrm{~F}$ NMR spectra. See DOI: $10.1039 / \mathrm{c} 5 \mathrm{cp} 00834 \mathrm{~d}$
}

Si-O-Si bonds. ${ }^{5}$ Previous work involving combined microcrystal $\mathrm{X}$-ray diffraction and solid state NMR has shown that the fluoride ions can be covalently bonded in to the framework, ${ }^{6-9}$ usually in small four membered ring cages and may even have a structure directing role in the pure silica clathrasil, octadecasil. ${ }^{10}$ In addition, the fluoride ions have been shown to strongly interact with the positive charge on the SDAs causing the organic molecules to order non-centrosymmetrically within the zeolite ITQ-4, even though the zeolite framework is centrosymmetric. ${ }^{11}$

Koller et al. were the first to show by solid state NMR that the fluoride ions are often incorporated in to the zeolite framework as the five coordinate species $\left[\mathrm{SiO}_{4 / 2} \mathrm{~F}\right]^{-12,13}$ The presence of these units, in the absence of fluoride motion, can easily be identified by ${ }^{29} \mathrm{Si}$ MAS NMR as a J-coupled doublet with a chemical shift of between -145 and -150 ppm and a J-coupling of around 160-170 Hz. In the case of fluoride motion then a broad averaged resonance centered around $-125 \mathrm{ppm}$ can be seen. So far, the locations of only a few fluoride ions in pure silica zeolites have been reported from X-ray diffraction (XRD) data. ${ }^{6,7,14-20}$ This is often due to the difficulties in locating the fluoride ions by $\mathrm{XRD}$, as they are isoelectronic with $\mathrm{OH}$ groups that are often present as defects in zeolite frameworks. ${ }^{21}$ The local structure of the $\left[\mathrm{SiO}_{4 / 2} \mathrm{~F}\right]^{-}$units reported by XRD, is often not the true local structure but is an average between $\left[\mathrm{SiO}_{4 / 2} \mathrm{~F}\right]^{-}$ and $\mathrm{SiO}_{4 / 2}$ units, due to the incomplete occupancy of the fluoride ions in the form of either static or dynamic disorder. ${ }^{22}$ This disorder often leads to the reporting of an average $\mathrm{F}-\mathrm{Si}$ bond distance, which is much longer (between 1.84-1.99 $\AA$ ) than the real distance (1.76-1.78 $\mathrm{A}$ ) in the five coordinate species. Previous work has shown that solid state NMR is an excellent probe of the local structure of zeolites and can be used to accurately locate fluoride ions within the framework. ${ }^{6,7,23}$

The framework structure of MFI-type zeolites has been known since $1978,{ }^{24}$ but it was not until 2001 onwards that the location of both the fluoride and the SDA (tetrapropylammonium) ions in the pure silica form, silicalite, were accurately determined. ${ }^{23,25}$ Although there has been some initial work on investigating the role of SDAs in MFI syntheses these have primarily focused on 
tetrapropylammonium (TPA) cations with little mention of the effects on or the role of the fluoride anions. ${ }^{26,27}$ In this paper we report our initial findings on the effects of varying the SDA on both the fluoride ordering within pure silica MFI and their potential structure directing roles.

The ${ }^{29} \mathrm{Si}\left\{{ }^{1} \mathrm{H}\right\}$ CP MAS NMR spectrum of as-synthesised [TPA]F,MFI shown in Fig. 1 can be deconvoluted into 12 peaks that are characteristic of the 12 silicon sites previously assigned by Fyfe $e t a l .{ }^{23}$ They showed that the fluoride ions are found within the $\left[4^{1} 5^{2} 6^{2}\right]$ cages, and at room temperature are dynamically disordered between two equivalent silicon sites that are mirrorrelated giving rise to the broad peak at $-125 \mathrm{ppm}$. It has been proposed that the rate of this dynamic disorder of the fluoride ions is fast compared to the NMR timescale, thus making the two silicon sites appear equivalent. ${ }^{23}$ Although no explanation of this dynamic disordering of the fluoride ions has been previously given, we believe that it is due to the distance between the fluoride and the positively charged nitrogen on the SDA cations being greater, and thus the coulombic interaction being smaller, than in other zeolites where static disorder is seen. To investigate this we synthesized two SDAs with three butyl arms and with increasing lengths of the forth arm to give methyltributylammonium (MTBA) and ethyltributylammonium (ETBA). In addition, an MFI sample using methyltripropylammonium (MTPA) was also synthesized to compare with the MTBA sample in order to determine the effects of the tributyl versus the tripropyl groups within the SDAs.

Fig. 2 shows the ${ }^{29} \mathrm{Si}\left\{{ }^{1} \mathrm{H}\right\}$ CP MAS NMR spectrum of [MTBA]F,MFI. It can be seen that there is substantial chemical shift resolution and there is clear evidence of a covalent $\mathrm{Si}-\mathrm{F}$ bond as shown by the peak centered at -146 ppm. Interestingly, this signal is relatively sharp and clearly split into a doublet $\left(J_{\mathrm{Si}-\mathrm{F}}=\right.$ $165 \mathrm{~Hz}$ ), unlike in the [TPA]-F,MFI sample. This indicates that the fluoride is incorporated into the framework and is statically disordered when the $\mathrm{MTBA}^{+}$cation is present. Indeed, the general appearance of the ${ }^{29} \mathrm{Si}$ spectrum is similar to that of [TPA]-F,MFI at $-50{ }^{\circ} \mathrm{C}$ where the motion has been frozen out. ${ }^{13}$ Deconvolution of the [MTBA]-F,MFI ${ }^{29} \mathrm{Si}$ spectrum shows that

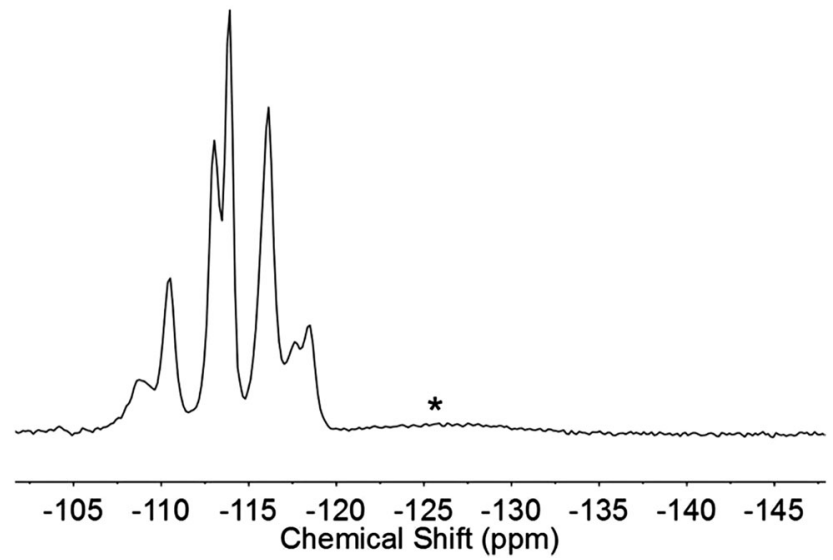

Fig. $1{ }^{29} \mathrm{Si}\left\{{ }^{1} \mathrm{H}\right\}$ CP MAS NMR spectrum of [TPA]-F,MFI collected at a spinning rate of $6 \mathrm{kHz}$, contact time of $7 \mathrm{~ms}$ and a recycle delay of $3 \mathrm{~s}$. The broad $\left[\mathrm{SiO}_{4 / 2} \mathrm{~F}\right]^{-}$peak is marked with an asterisk (*).

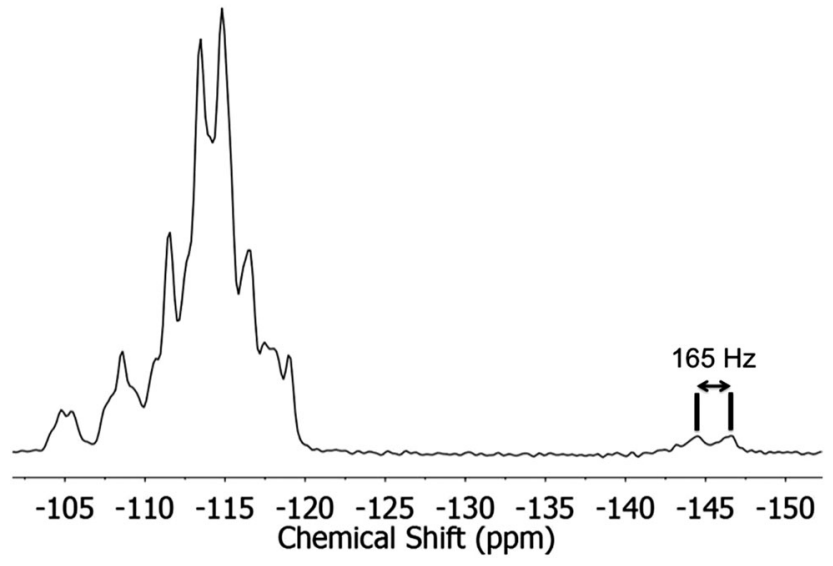

Fig. $2{ }^{29} \mathrm{Si}\left\{{ }^{1} \mathrm{H}\right\}$ CP MAS NMR spectrum of [MTBA]-F,MFI collected at a spinning rate of $6 \mathrm{kHz}$, contact time of $7 \mathrm{~ms}$ and a recycle delay of $3 \mathrm{~s}$.

there are 24 tetrahedral Si sites and not the 12 sites expected for Pnma symmetry as seen for [TPA]-F,MFI at $298 \mathrm{~K}$. This increase in Si sites can be explained by examining the local structure of the MFI framework where the fluoride ions are found. As NMR probes the local structure of a material, the true symmetry of the $\left[4^{1} 5^{2} 6^{2}\right]$ cages is in fact lower than that determined from the crystal structure due to the static fluoride disorder. The ${ }^{29} \mathrm{Si}\left\{{ }^{1} \mathrm{H}\right\}$ NMR spectrum indicates that the fluoride ions only occupy one site within the $\left[4^{1} 5^{2} 6^{2}\right]$ cage and hence on a local scale shows 24 tetrahedral sites whilst still displaying Pnma symmetry by powder X-ray diffraction.

On increasing the length of one of the alkyl chains from methyl to larger alkyl groups we predicted that the coulombic interaction between the positively charged nitrogen and the fluoride ion would be reduced, due to the increase in distance between the two, leading to a change from static to dynamic disorder. This was confirmed by collecting the ${ }^{29} \mathrm{Si}\left\{{ }^{1} \mathrm{H}\right\}$ CP MAS NMR spectrum of [ETBA]-F,MFI shown in Fig. 3.

It can be seen that this spectrum shows similarities to that of both the TPA and MTBA samples. Interestingly though the

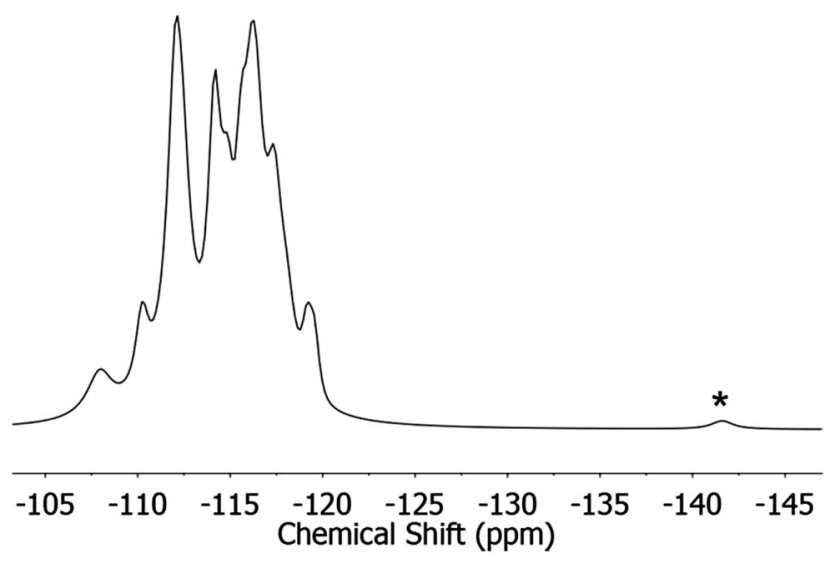

Fig. $3{ }^{29} \mathrm{Si}\left\{{ }^{1} \mathrm{H}\right\}$ CP MAS NMR spectrum of [ETBA]-F,MFI collected at a spinning rate of $6 \mathrm{kHz}$, contact time of $7 \mathrm{~ms}$ and a recycle delay of $3 \mathrm{~s}$. The $\left[\mathrm{SiO}_{4 / 2} \mathrm{~F}\right]^{-}$peak is marked with an asterisk (*). 


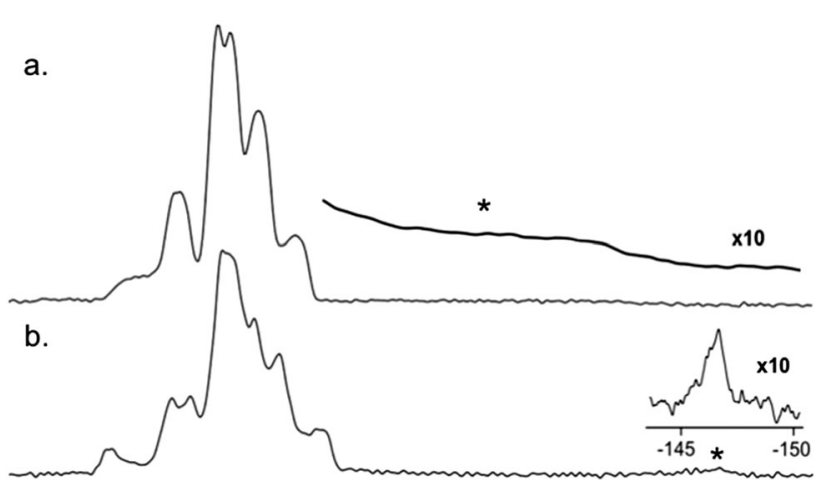

$-100-105-110-115-120-125-130-135-140-145-150$ Chemical Shift (ppm)

Fig. $4{ }^{29} \mathrm{Si}\left\{{ }^{1} \mathrm{H}\right\}$ CP MAS NMR spectra of [MTPA],F-MFI collected at a spinning rate of $6 \mathrm{kHz}$, contact time of $10 \mathrm{~ms}$ and a recycle delay of $3 \mathrm{~s}$ at (a) $295 \mathrm{~K}$ and (b) $233 \mathrm{~K}$. The $\left[\mathrm{SiO}_{4 / 2} \mathrm{~F}\right]^{-}$peaks are marked with an asterisk ${ }^{*}$ ) and shown as inset expansions.

peak corresponding to the $\left[\mathrm{SiO}_{4 / 2} \mathrm{~F}\right]^{-}$environment does not resemble that for either of the other two SDAs. This peak centered at $-142 \mathrm{ppm}$ has characteristics somewhere between those for the TPA and MTBA based samples and in fact resembles the [TPA]-F,MFI at around $-40{ }^{\circ} \mathrm{C} .{ }^{13}$ This is most likely due to dynamic disorder of the $\left[\mathrm{SiO}_{4 / 2} \mathrm{~F}\right]^{-}$sites taking place at a rate much slower than that seen previously for [TPA]F,MFI at a similar temperature of $298 \mathrm{~K}$.

On changing the SDA cation to methyltripropylammonium (MTPA), a significant difference in the $298 \mathrm{~K}{ }^{29} \mathrm{Si}\left\{{ }^{1} \mathrm{H}\right\}$ CP MAS NMR spectrum is observed (Fig. 4a). Unlike the spectra of the TPA, MTBA or ETBA MFI samples the [MTPA]-F,MFI material shows significantly less chemical shift resolution.

The spectrum displays a very broad peak of a dynamically disordered $\left[\mathrm{SiO}_{4 / 2} \mathrm{~F}\right]^{-}$environment centered at $-130 \mathrm{ppm}$, which is in stark contrast to that of the related [MTBA]-F,MFI sample. This simple change from tributyl to tripropyl groups seems to indicate that the presence of the longer butyl arms ensures that the orientation of the SDA in the MFI framework is likely to be with the shortest arm (methyl or ethyl) closest to the fluoride ion. In the MTPA sample however, it would appear that the propyl arms are just short enough and therefore enable a sufficient coulombic interaction between the $\mathrm{N}^{+}$and the $\mathrm{F}^{-}$ ions to allow the SDA to orientate with either the methyl or one of the propyl groups closest to the fluoride ion and thus preventing static disorder occurring. This orientation effect is potentially confirmed by observing the multiple resonances in the ${ }^{13} \mathrm{C}\left\{{ }^{1} \mathrm{H}\right\}$ CP MAS spectrum (ESI $\dagger$ ), indicating more than one orientation of the MTPA cations within the MFI framework. To see whether the dynamic disorder in the [MTPA]-F,MFI sample was causing the lack of chemical shift resolution observed at $298 \mathrm{~K}$, a spectrum was collected at $233 \mathrm{~K}$ (Fig. 4b). Lowering the temperature provides a substantial improvement in the chemical shift resolution and as observed for [TPA]-F,MFI at similar temperatures the fluoride motion is frozen out to give a broadened J-coupled doublet at $-146 \mathrm{ppm}$.

\section{Conclusions}

In conclusion, this is the first example of a zeolite displaying both static and dynamic disorder of the $\left[\mathrm{SiO}_{4 / 2} \mathrm{~F}\right]^{-}$environments at room temperature by simply changing the size of the SDA. Our initial results suggest that the size/shape of the SDA may play an important role in determining the type of disorder seen in the fluoride ions and it is suggested that this is due to the strength of the coulombic interaction between the SDA and fluoride ions. Further work is currently in progress to study the interaction between the SDA and fluoride ions in a variety of MFI samples using the dipolar couplings. Our future studies will focus on investigating these SDA effects in other zeolite framework types such as IFR.

\section{Acknowledgements}

The authors would like to thank Keele University and the University of St Andrews for providing a PhD studentship for SLB. PW would like to thank the EPSRC for funding (EP/E041825/1). RJD would like to thank Prof. Colin Fyfe of the University of British Columbia for useful discussions and for providing NMR spectrometer time for initial results.

\section{References}

1 J. L. Guth, H. Kessler, J. M. Higel, J. M. Lamblin, J. Patarin, A. Seive, J. M. Chezeau and R. Wey, ACS Symp. Ser., 1989, 398, 176-195.

2 A. Kuperman, S. Nadimi, S. Oliver, G. A. Ozin, J. M. Garces and M. M. Olken, Nature, 1993, 365, 239-242.

3 P. A. Barrett, M. A. Camblor, A. Corma, R. H. Jones and L. A. Villaescusa, Chem. Mater., 1997, 9, 1713.

4 M. A. Camblor, A. Corma, P. Lightfoot, L. A. Villaescusa and P. A. Wright, Angew. Chem., Int. Ed., 1997, 36, 2659-2661.

5 M. A. Camblor, L. A. Villaescusa and M. J. Diaz-Cabanas, Top. Catal., 1999, 9, 59-76.

6 R. J. Darton, D. H. Brouwer, C. A. Fyfe, L. A. Villaescusa and R. E. Morris, Chem. Mater., 2004, 16, 600-603.

7 C. A. Fyfe, D. H. Brouwer, A. R. Lewis, L. A. Villaescusa and R. E. Morris, J. Am. Chem. Soc., 2002, 124, 7770-7778.

8 A. Burton, R. J. Darton, M. E. Davis, S. J. Swang, R. E. Morris, I. Ogino and S. I. Jones, J. Phys. Chem. B, 2006, 110, 5273-5278.

9 R. E. Morris, Z. Kristallogr., 2007, 33-38.

10 C. A. Fyfe, A. R. Lewis, J. M. Chezeau and H. Grondey, J. Am. Chem. Soc., 1997, 119, 12210-12222.

11 I. Bull, L. A. Villaescusa, S. J. Teat, M. A. Camblor, P. A. Wright, P. Lightfoot and R. E. Morris, J. Am. Chem. Soc., 2000, 122, 7128-7129.

12 H. Koller, A. Wolker, H. Eckert, C. Panz and P. Behrens, Angew. Chem., Int. Ed., 1997, 36, 2823-2825.

13 H. Koller, A. Wolker, L. A. Villascusa, M. J. Diaz-Cabanas, S. Valencia and M. A. Camblor, J. Am. Chem. Soc., 1999, 121, 3368-3376. 
14 L. A. Villaescusa, P. S. Wheatley, I. Bull, P. Lightfoot and R. E. Morris, J. Am. Chem. Soc., 2001, 123, 8797-8805.

15 P. A. Barrett, M. A. Camblor, A. Corma, R. H. Jones and L. A. Villaescusa, J. Phys. Chem. B, 1998, 102, 4147-4155.

16 L. A. Villaescusa, I. Bull, P. S. Wheatley, P. Lightfoot and R. E. Morris, J. Mater. Chem., 2003, 13, 1978-1982.

17 M. A. Camblor, M. J. Diaz-Cabanas, J. Perez-Pariente, S. J. Teat, W. Clegg, I. J. Shannon, P. Lightfoot, P. A. Wright and R. E. Morris, Angew. Chem., Int. Ed., 1998, 37, 2122-2126.

18 S. I. Zones, R. J. Darton, R. E. Morris and S. J. Hwang, J. Phys. Chem. B, 2005, 109, 652-661.

19 D. S. Wragg, R. Morris, A. W. Burton, S. I. Zones, K. Ong and G. Lee, Chem. Mater., 2007, 19, 3924-3932.

20 X. B. Yang, M. A. Camblor, Y. Lee, H. M. Liu and D. H. Olsen, J. Am. Chem. Soc., 2004, 126, 10403-10409.
21 M. Arranz, J. Perez-Pariente, P. A. Wright, A. M. Z. Slawin, T. Blasco, L. Gomez-Hortiguela and F. Cora, Chem. Mater., 2005, 17, 4374-4385.

22 M. P. Attfield, C. R. A. Catlow and A. A. Sokol, Chem. Mater., 2001, 13, 4708-4713.

23 C. A. Fyfe, D. H. Brouwer, A. R. Lewis and J. M. Chezeau, J. Am. Chem. Soc., 2001, 123, 6882-6891.

24 G. T. Kokotailo, S. L. Lawton, D. H. Olsen and W. M. Meier, Nature, 1978, 272, 437-438.

25 E. Aubert, F. Porcher, M. Souhassou, V. Petricek and C. Lecomte, J. Phys. Chem. B, 2002, 106, 1110-1117.

26 S. L. Burkett and M. E. Davis, J. Phys. Chem., 1994, 98, 4647-4653.

27 S. L. Burkett and M. E. Davis, Chem. Mater., 1995, 7, 920-928. 